\title{
A SUPPRESSING EFFECT OF $\varepsilon$-AMINO-N-CAPROIC ACID ON THE BLEEDING OF DOGS, PRODUCED WITH THE ACTIVATION OF PLASMIN IN THE CIRCULATORY BLOOD
}

\author{
SHOSUKE OKAMOTO,M.D.*, TETSUO NAKAJIMA, M.D.**, UTAKO, \\ OKAMOTO, M.D.****, HIDEFUMI WATANABE, M.D., YUTAKA \\ IGUCHI, M.D., TEIJI IGAWA, M.D., CHING-CHUN CHIEN, M.D. \\ and TAKASHI HAYASHI, M.D.*** \\ Research Project on Plasmin and Antiplasmin \\ Department of Physiology, Division I, Kobe Medical College \\ Dapartment of Physiology, Department of Anesthesiology, \\ School of Medicine, Keio University \\ Department of Surgery, Tokyo Dental College
}

(Received for publication August 31, 1959)

\section{INTRODUCTION}

The more precise concept of fibrinolysis has long been inquired by the members of workers in different fields and from different angles; yet the evidences obtained are so contraversial that some fundamental investigations are, and will be, required to formulate the advanced concept of the phenomena of fibrinolysis which have been observed in various conditions of patients and experimental animals.

In fact, current interest on fibrinolysis has been raised by the promising development of fibrinolytic therapy(1) on such disorders as thromboembolic disease, which led some workers to regard the fibrinolysis as one of the repairing mechanism of a body(2).

However, another concept has been made from the very intense, pathological fibrinolysis, which was observed in some fatal conditions as so called "endless bleeding" of patients. One of the simplest examples of such pathological fibrinolysis, reported by Ratnoff ${ }^{(3)}$ in 1952 , was that his patient died after an operation for endless bleeding, the blood examination indicating very intense plasmin

* Professor, Department of Physiology, Division I, Kobe Medical College; General secretary of the Project.

** Professor, Department of Surgery, Tokyo Dental College.

*** Professor, Department of Physiology, School of Medicine, Keio University; Vicechairman of the Committee of the Project.

**** Instructor, Department of Physiology, School of Medicine, Keio University; Business secretary of the Project. 
activity but no other significant primary causes of the bleeding. By many other investigators it has been also reported that a- or hypo-fibrinogenemia caused by pathological fibrinolysis resulted in the enhanced bleeding tendencies of surgical and obstetrical patients.

Thus the contemporary achievement poses two different tasks. One is investigation on the favourable effect of fibrinolysis just as seen in fibrinolytic therapy. The other is on the conceptive effect of pathologically accelerated fibrinolysis as seen in hemorrhage of dramatic intensity of certain patients.

Here a special attention was paid by us to the evidence that such an intense hemorrhage was not responsible to the usual treatments. This is the reason why it was undertaken by S. Okamoto and his colleagues to search for a synthetized antiplasmic substance in 1947. After having examined more than 300 kinds of the synthetized chemical compounds, $\varepsilon$-amino-n-caproic acid* was discovered as one of the most effective substances to suppress specifically the activation of plasmin and/or the plasmin activity in vitro and in vivo(4). Side actions of $\varepsilon$ were confirmed to be negligible even when a considerably large amount of $\varepsilon$ was repeatedly administrated to experimental animals.

Taking advantage of the discovery of $\varepsilon$, the following animal experiments were designed by us to study (1) the relation of the intense fibrinolysis to hemorrhage and (2) the effect of administration of $\varepsilon$ to the fibrinolysis and to the accompanied bleeding.

\section{METHODS}

a) Medium sized dogs, which had a healthy appearance and weighed $8 \mathrm{~kg}$ to $12 \mathrm{~kg}$, were used. Narcotizing the dogs by the intravenous injection of sodium pentobarbiturate (sodium 5-ethyl-5-(1-methylbutyl)-barbiturate) solution, the blood pressure was recorded by the ordinary manometer, which was connected with the catheter inserted into the carotid artery. The trachea tube was inserted in the trachea to make ventilation easier. Through a small tube inserted in the trachea tube, oxygen was supplied to prevent anoxia of dogs. Injections of adequate cardiotonic agents to dogs were made when the condition of the dog became weakened.

b) It has generally been accepted that: (1) The blood of dogs shows a weak or no response to streptokinase**. (2) Human serum can be strongly activated with SK because of the presence of the proactivator-activator-system which is found in human serum and is very responsive to SK. (3) Plasminogen

\footnotetext{
* abbreviated as $\varepsilon$ in this text.

** hereinafter abbreviated as SK.
} 
in dog's blood can be easily activated with SK in the presence of a small amount of human serum. Thus, based upon the results obtained from the fundamental experiments as described later, the following method was adopted to activate plasmin system in the circulatory blood of dogs. A kind of the Castellani's absorption method was adopted to remove natural aggulutinins of human serum to dog's red cells. About $50 \mathrm{cc}$ of human serum was kept for 30 minutes at $0^{\circ} \mathrm{C}$ with an equal amount of washed red cells of dogs. By centrifuging the mixture at the refrigerated centrifuge, $50 \mathrm{cc}$ of human serum was obtained. The sample was kept in a cold room. Before the administration of the serum to dogs, it was warmed for 15 minutes at room temperature and injected intravenously to dogs. It is demonstrated in the present paper that the administration of this human serum to the dogs caused no unfavourable side effects. According to the blood examination made on the blood sample taken after the administration of the human serum, there was only a small change of plasmin activity in the blood. Then, a given amount of SK was injected intravenously to dogs in order to cause the strong activation of plasmin in the circulatory blood.

c) Blood samples were taken time to time from dog veins during the experiment. Plasmin activity and the content of plasma fibrinogen in the sample were determined by the routine methods $(5,6,7)$. Fibrinogen content in plasma was gravimetrically measured according to the Gramm's method.

The method to examine variations of the bleeding tendency of dogs under given conditions was as follows:

(1) The skin of dog was incised 5-6 cm long at several parts on the trunk, and each incision was opened across about $3 \mathrm{~cm}$ wide.

(2) A certain size of filter paper, which had been weighed previously, was closely placed on the wound surface for 30 seconds, so that the blood oozed from the wound surface was absorbed into the filter paper as much as possible.

(3) The amount of blood absorbed was calculated by measuring again the weight of the filter paper used. The weight of blood absorbed was understood to indicate the degree of "oozing."

d) The effect of the intravenous administration of $\varepsilon$ on plasmin activity as well as on the bleeding tendency was examined, and appropriate and necessary controls were taken.

Details of the experimental method were given in the case report of animal experiments. 


\section{RESULTS}

a) Influence of the addition of a small amount of human serum on the activation of plasminogen with $S K$ in the blood of dogs.

These experiments, carried out in vitro, were undertaken to determine quantitative details of the experimental method to activate the plasmin system in the circulatory blood of dogs by the intravenous administration of human serum and SK. Fifteen test tubes were divided into three groups, A, B and C, respectively. $0.5 \mathrm{cc}$ of the oxalated plasma of dogs, various amounts of SK dissolved in $0.1 \mathrm{ce}$ of a physiological saline solution, $0.05 \mathrm{cc}$ of human serum and a physiological saline solution of $\varepsilon$ were mixed in different combinations as described in the following table. Then, fibrin clot was made by adding $0.05 \mathrm{cc}$ of $2 \% \mathrm{CaCl}_{2}$ and some amount of physiological saline solution to make total volume $1.0 \mathrm{cc}$. Test tubes were then incubated at $37^{\circ} \mathrm{C}$ for 30 minutes. After that, the total dry weight of fibrin in each reaction mixture was gravimentrically measured according to the method of Gramm.

The following table shows percentages of the breakdown of fibrin in each tube: (Taking standard fibrin as 100 )

\begin{tabular}{cccccc}
\hline $\begin{array}{c}\text { Test } \\
\text { tube } \\
\text { No. }\end{array}$ & $\begin{array}{c}\text { Reaction } \\
\text { (cc) }\end{array}$ & $\begin{array}{c}\text { Human serum } \\
\text { (cc) }\end{array}$ & $\begin{array}{c}\text { SK } \\
\text { (unit) }\end{array}$ & $\begin{array}{c}2.5 \% \text { c solution } \\
\text { (cc) }\end{array}$ & $\begin{array}{c}\text { Percentage of } \\
\text { the breakdown } \\
\text { of fibrin }\end{array}$ \\
\hline A-1 & 0.5 & - & 0 & - & 0 \\
A-2 & 0.5 & - & 10 & - & 3 \\
A-3 & 0.5 & - & 100 & - & 9 \\
A-4 & 0.5 & - & 1,000 & - & 70 \\
A-5 & 0.5 & - & 10,000 & - & 100 \\
\hline B-1 & 0.5 & 0.05 & 0 & - & 0 \\
B-2 & 0.5 & 0.05 & 10 & - & 100 \\
B-3 & 0.5 & 0.05 & 100 & - & 100 \\
B-4 & 0.5 & 0.05 & 1,000 & - & 100 \\
B-5 & 0.5 & 0.05 & 10,000 & - & 100 \\
\hline C-1 & 0.5 & 0.05 & 0 & 0.1 & 0 \\
C-2 & 0.5 & 0.05 & 10 & 0.1 & 3 \\
C-3 & 0.5 & 0.05 & 100 & 0.1 & 2 \\
C-4 & 0.5 & 0.05 & 1,000 & 0.1 & 100 \\
C-5 & 0.5 & 0.05 & 10,000 & 0.1 & \\
\hline
\end{tabular}

From the above mentioned results, we confirmed that the addition of $0.05 \mathrm{cc}$ of human serum to $0.5 \mathrm{cc}$ of dog plasma in the presence of 10 units of SK resulted in sufficient activation of plasmin and the complete breakdown of fibrin, but, when $\varepsilon$ was added, the breakdown of fibrin by plasmin was strongly arrested. These results. presented enough evidence for determining the experimental conditions of sufficient activation of plasmin in the circulatory blood of dogs. On the basis of the results, $50 \mathrm{cc}$ of human serum and 10,000 units of SK were administrated intravenously to dogs weighing about $10 \mathrm{~kg}$, we expecting sufficient activation of plasmin in the circulatory blood. 
b) Influence of the sole administration of $S K$ on plasmin activity and oozing.

Case No. 1: Experimental Record No. 3. Date: Oct. 25, 1958.

Dog's name: Elizabeth Adult, Sex: Female, Body weight: Ca. $10 \mathrm{~kg}$.

(1) Control blood sample was taken at $3: 00 \mathrm{p} . \mathrm{m}$. and the following result was obtained: i) Natural clot lysis test: The coagulation time was 4 minutes 30 seconds and clot lysis did not occur within 3 hours. ii) The content of plasma fibrinogen was $630 \mathrm{mg} / \mathrm{dl}$ of plasma.

(2) At 3:45 p.m., 20,000 units of SK, which was dissolved in 2 ce of physiological saline solution, was injected intravenously into the dog. At 3:55 p.m., a second blood sample was taken. Plasmin activity of this sample was examined by the method of natural clot lysis test. The coagulation time was 3 minutes 30 seconds and clot lysis occurred in 50 minutes. The content of plasma fibrinogen was $625 \mathrm{mg} / \mathrm{dl}$ of plasma.

(3) Results described in item (1) and (2) indicated that the sole administration of a sufficient amount of SK to the dog was accompanied only by slight activation of the plasmin system in the circulatory blood and that, by the sole administration of SK, any noticiable oozing from the incised wound was not observed at all.

(4) It was indicated also (i) that, by the sole administration of SK, there was only a very weak response of the plasmin system in the circulatory blood of the dog, without accompanying any sign of oozing, and (ii) that these results coincided with the results obtained in vitro under similar experimental conditions described in A group in the above table.

Case No. 2: Experimental Record No. 24. Date: May 30, 1959.

Dog's name: James Adult, Sex: Male, Body weight: Ca. $9 \mathrm{~kg}$.

(1) At 4:09 p.m., the blood pressure was $120-130 \mathrm{~mm} \mathrm{Hg}$ and oozing was $11.5 \mathrm{mg} / \mathrm{sec}$. Control blood sample was taken at the same time and the following result was obtained. i) Natural clot lysis test: The coagulation time was 4 minutes and 10 seconds, and lysis did not occur within 3 hours. ii) Lewis' euglobulin lysis test: 2.38 units $/ 0.5 \mathrm{cc}$ of plasma. iii) $\Delta$ of absorbance at $280 \mathrm{~m} \mu$ U.V.: 0.008 . iv) Whole clot lysis test: 8 days. v) The content of plasma fibrinogen: $710 \mathrm{mg} / \mathrm{dl}$ of plasma.

(2) At 4:23 p.m., 50,000 units of SK was injected intravenously into the dog. At 4:26 p.m., a second blood sample was taken and the following result was obtained. i) Natural clot lysis test: The coagulation time was 3 minutes 10 seconds and lysis of the clot did not occur within 3 hours. ii) Lewis' euglobulin lysis test: 2.38 units $/ 0.5 \mathrm{cc}$ of plasma. iii) $\Delta$ of absorbance of $280 \mathrm{~m} \mu$ U.V.: 0.023 . iv) Whole clot lysis test: 5 days. v) The content of plasma fibrinogen: $600 \mathrm{mg} / \mathrm{dl}$ of plasma.

Throughout the experiment, blood pressure did not show any change and no increased oozing was observed.

(3). It was indicated (i) that, by the intravenous administration of SK, plasmin activity in the circulatory blood of the dog was only very slightly activated without accompanying any sign of increased bleeding, and (ii) that these results coincided with those obtained in vitro tests described in $\mathrm{A}$ group in the above table. 


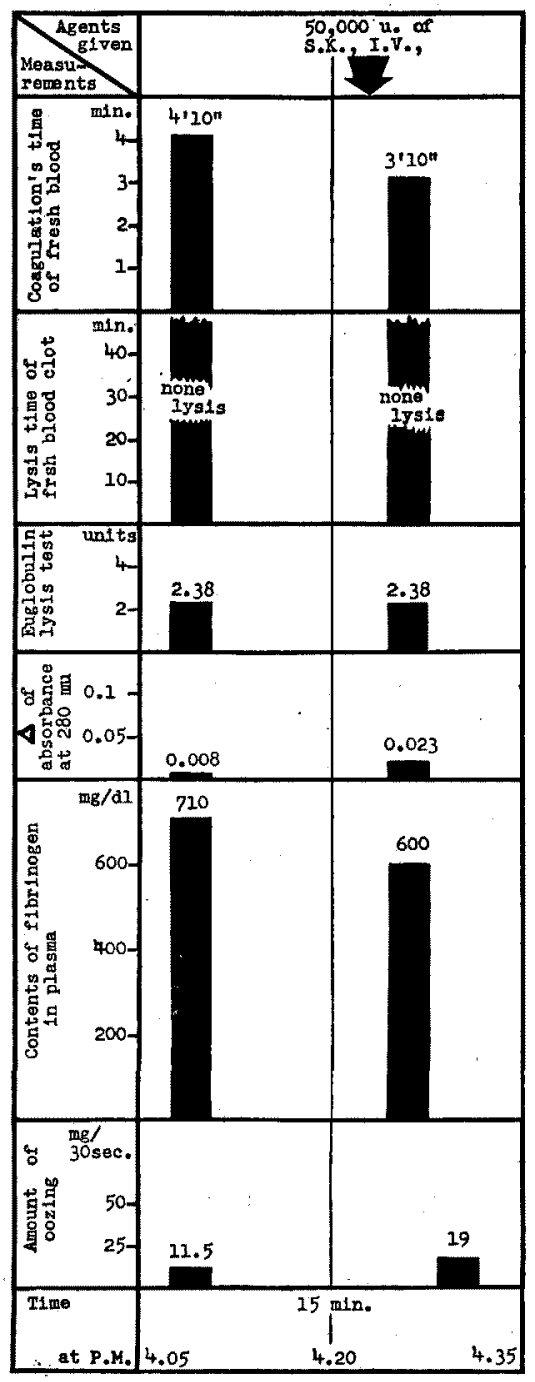

Fig. 1. Influence of the sole administration of S.K. on plasmin activity and oozing.

c) Influence of the administration of human serum and $S K$ on plasmin activity and oozing.

Case No. 3: Experimental Record No. 4. Date: Oct. 31, 1958.

Dog's name: Shiro Adult, Sex: Male, Body weight: Ca. $10 \mathrm{~kg}$.

(1) At 3:36 p.m., control blood sample was taken. Plasmin activity of the sample was examined and the following result was obtained. i) Natural clot lysis test: The coagulation time was 7 minutes and the natural clot lysis time was 28 minutes. ii) The content of plasma fibrinogen: $642 \mathrm{mg} / \mathrm{dl}$ of plasma. At 4:06 p.m., the amount of oozing was $9 \mathrm{mg} / 30$ sec. 
(2) At 4:10 p.m., $50 \mathrm{cc}$ of human serum which underwent Castellani's absorption, was injected intravenously. A second blood sample was taken at 4:12 p.m. and the following result was obtained. Natural clot lysis test: The coagulation time was 4 minutes 30 seconds and the natural colt lysis time 25 minutes. Increased oozing was not observed. The blood pressure was $155-165 \mathrm{~mm} \mathrm{Hg}$.

These results showed that natural clot lysis in the blood and oozing was not enhanced by the sole administration of human serum.

(3) At 4:38 p.m., 100,000 units of SK was administered intravenously to the dog. Plasmin activity of the sample, which was taken at 4:40 p.m. was examined. i) The coagulation of fresh blood did not occur within 3 hours, indicating a strong activity of plasmin in the blood sample. The amount of oozing was $10 \mathrm{mg} / 30 \mathrm{sec}$ and the blood pressure was $110 \mathrm{~mm} \mathrm{Hg}$. ii) The blood pressure was maintained

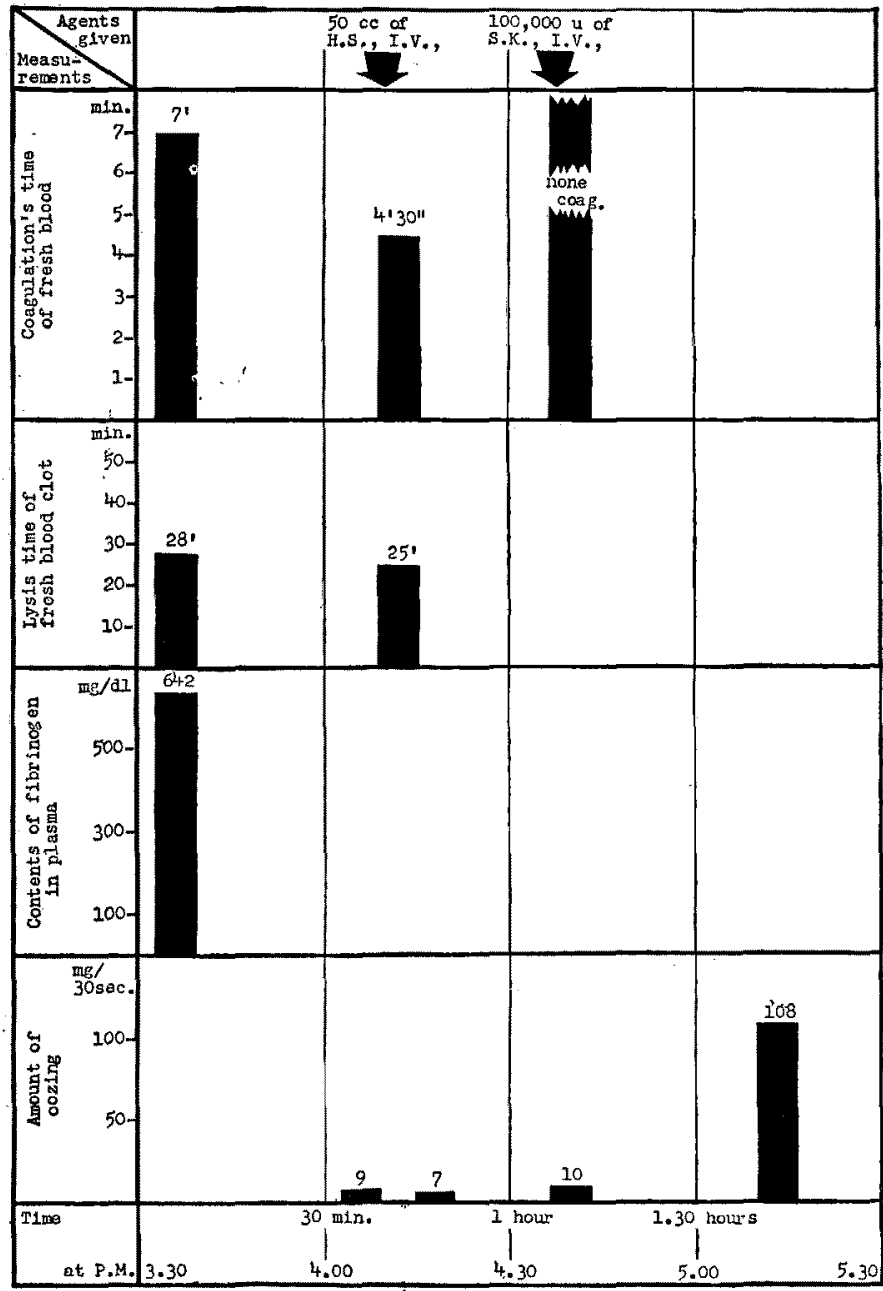

Fig. 2. Influence of the administration of human serum and S.K. on plasmin activity of oozing. 
254 S. Okamoto, Nakajima, U. Okamoto, Watanabe, Iguchi, Igawa, Chien and Hayashi

at $175-165 \mathrm{~mm} \mathrm{Hg}$, by the administration of Noradrenalin, upon which oozing started to occur very strongly. The amount of oozing measured increased to $108 \mathrm{mg} / 30$ sec.

(4) This result showed (i) that plasmin activity in the circulatory blood and oozing from the incised wound remained actually unchanged by the preliminary administration of human serum which underwent Castellani's absorption and (ii) that by the successive administration of $\mathrm{SK}$ in addition to human serum, plasmin activity became high and oozing was distinctively enhanced, just as expected from the results obtained in vitro tests of $B$ group in the above table.

d) Inflence of the administration of $\varepsilon$ on the high activity of plasmin and oozing caused by the administration of human serum plus $S K$.

Case No. 4: Experimental Record No. 5. Date: Nov. 5, 1958.

Dog's name: Robert Adult, Sex: Male, Body weight: Ca. $10 \mathrm{~kg}$.

(1) Control blood sample was taken at 3:15 p.m. and the following results were obtained.

i) Natural clot lysis test: The coagulation time was 8 minutes 30 seconds and clot lysis did not occure within 3 hours. ii) Lewis' euglobulin Iysis test: 2.5 units $/ 0.5$ ce of plasma. iii) $\Delta$ of absorbance at $280 \mathrm{~m} \mu$ U.V. was not detectable. iv) The content of plasma fibrinogen: $852 \mathrm{mg} / \mathrm{dl}$ of plasma. The blood pressure was $125-135 \mathrm{~mm} \mathrm{Hg}$ and oozing did not occur from the incised wound.

(2) At 3:36 p.m., $50 \mathrm{cc}$ of human serum which underwent Castellani's absorption was injected intravenously and at 4:23 p.m., 70,000 units of $\mathrm{SK}$ was administered intravenously to the dog. Plasmin activity of the sample, which was taken at 4:26 p.m. was examined and the result was as follows. i) Natural clot lysis test: The coagulation time was 5 minutes 30 seconds and lysis time of the clot was 45 minutes. ii) Lewis' euglobulin lysis test: More than 5.0 units/0.5 cc of plasma. iii) $\Delta$ of absorbance at $280 \mathrm{~m} \mu$ U.V.: 0.24 . iv) The content of plasma fibrinogen: $682 \mathrm{mg} / \mathrm{dl}$ of plasma. At the same time, the blood pressure, which underwent a transient fall during the intravenous administration of SK, recovered nearly to normal by the intravenous administration of Noradrenalin. The amount of oozing was $10 \mathrm{mg} / 30 \mathrm{sec}$.

This result showed that plasmin in the circulatory blood of the dog was activated very strongly by the intravenous administration of human serum plus $\mathrm{SK}$.

(3) At 4:50 p.m., when the blood pressure had recovered to normalcy by the intravenous administration of $100 \mathrm{cc}$ of Dextran, oozing was observed, and the amount of oozing was $70 \mathrm{mg} / 30 \mathrm{sec}$. Oozing occurred strongly after the recovery of the blood pressure. At 5:05 p.m., about $150 \mathrm{cc}$ of Dextran was administered intravenously.

(4) At 5:15 p.m., $100 \mathrm{cc}$ of $5 \% \varepsilon$ solution was administrated intravenously. The blood pressure recovered to normalcy, and the amount of oozing was $40 \mathrm{mg} / 30$ sec. At the same time, a third blood sample was taken and plasmin activity examined. The result was as follows. i) Lewis' eugloblin lysis test: 2.5 units/0.5 ce of plasma. ii) $\Delta$ of absorbance at $280 \mathrm{~m} \mu$ U.V.: 1.08 . iii) The content of plasma fibrinogen: $308 \mathrm{mg} / \mathrm{dl}$ of plasma. 
(5) At 6:04 p.m., $20 \mathrm{cc}$ of $5 \% \varepsilon$ solution was administrated supplementally further to decrease plasmin activity. The last blood sample was taken at $6: 35 \mathrm{p.m}$., and plasmin activity was examined. The result was as follows. i) Lewis' euglobulin lysis test: 0.8 units $/ 0.5$ ce of plasma. ii) $\Delta$ of absorbance at $280 \mathrm{~m} \mu$ U.V.: was not detactable. iii) The content of plasma fibrinogen was $472 \mathrm{mg} / \mathrm{dl}$ of plasma. At the same time, the amount of oozing was $25 \mathrm{mg} / 30 \mathrm{sec}$ and the blood pressure remained normal.

This result showed that plasmin activity and oozing caused by the administration of human serum plus SK had decreased by the intravenous administration of $\varepsilon$.

Case No. 5: Experimental Record No. 17. .Date: April 13, 1959.

Dog's name: Jupiter II Adult, Sex: Male, Body weight: Ca. $10 \mathrm{~kg}$.

(1) At 4:00 p.m., control blood sample was taken. Plasmin activity was examined and the result was as follows. i) Natural clot lysis test: . The coagulation time of the fresh blood was 2 minutes and the lysis time of natural clot was 21 minutes. ii) Lewis' euglobulin lysis test: $0.81 \mathrm{units} / 0.5 \mathrm{cc}$ of plasma. iii) $\Delta$ of absorbance at $280 \mathrm{~m} \mu \mathrm{U} . \mathrm{V}$. was not detectable. iv) The contents of plasma fibrinogen: 720 $\mathrm{mg} / \mathrm{dl}$ of plasma.

The blood pressure was $130-135 \mathrm{~mm} \mathrm{Hg}$ at $4: 23 \mathrm{p} . \mathrm{m}$. The amount of oozing was $11 \mathrm{mg} / 30 \mathrm{sec}$.

(2) At 4:29 p.m., $50 \mathrm{cc}$ of human serum was injected intravenously into the dog. The second blood sample was taken at 4:30 p.m. The plasmin activity of the sample was as follows. i) Natural clot lysis test: The coagulation time of the natural clot was 3 minutes and the lysis time was 16 minutes. ii) Lewis' euglobulin lysis test: 1.47 units $/ 0.5 \mathrm{cc}$ of plasma. iii) $\Delta$ of absorbance at $280 \mathrm{~m} \mu$ U.V. was negative. iv) The content of plasma fibrinogen: $640 \mathrm{mg} / \mathrm{dl}$ of plasma.

The blood pressure was $125-130 \mathrm{~mm} \mathrm{Hg}$. The amount of oozing was $5 \mathrm{mg} / 30$ sec.

These results showed that, by the administration of human serum, plasmin activity was little changed and the amount of oozing was not increased.

(3) At 4:43 p.m., 70,000 units of SK was administered intravenously to the dog and the third blood sample was taken at $4: 55 \mathrm{p} . \mathrm{m}$. The plasmin activity of the sample was examined. i) Natural clot lysis test: The coagulation time was 3 minutes 30 seconds and the lysis time 16 minutes 30 seconds. ii) Lewis' euglobulin lysis test: 6.0 units $/ 0.5 \mathrm{cc}$ of plasma. iii) $\Delta$ of absorbance at $280 \mathrm{~m} \mu$ U.V. was not detectable. iv) The content of plasma fibrinogen: $260 \mathrm{mg} / \mathrm{dl}$ of plasma. At $4: 55$ p.m., the blood pressure was $130-135 \mathrm{~mm} \mathrm{Hg}$ and oozing was increased to $35 \mathrm{mg} / 30 \mathrm{sec}$.

(4) At 5:06 p.m., the intravenous administration of 30,000 units of SK was carried out supplementally with intent to enhance the activation of plasmin as much as possible.

(5) At 5:10 p.m., blood examination was carried out and the result was as follows. i) Natural clot lysis test: The coagulation time was 3 minutes and the lysis 
time 6 minutes. ii) Lewis' euglobulin lysis test: 5.0 units $/ 0.5$ cc of plasma. iii) $\Delta$ of absorbance at $280 \mathrm{~m} \mu$ U.V. was negative. iv) The content of plasma fibrinogen: $220 \mathrm{mg} / \mathrm{dl}$ of plasma.

At 5:11 p.m., the blood pressure was $120-130 \mathrm{~mm} \mathrm{Hg}$. Oozing was observed to have increased to $38 \mathrm{mg} / 30 \mathrm{sec}$.

(6) Twenty cubic centimentres of $5 \% \varepsilon$ solution was injected intravenously to the dog at $5: 46$ p.m., we expecting to suppress plasmin activity. A blood sample was taken at 5:56 p.m. and the result obtained was as follows: i) Natural clot lysis test: The coagulation time was 2 minutes 30 seconds and lysis of the clot did not occur within 3 hours. ii) Lewis' euglobulin lysis test: 1.56 units $/ 0.5$ ce of plasma. iii) $\Delta$ of absorbance at $280 \mathrm{~m} \mu$ U.V. was negative. iv) The content of plasma fibrinogen: $460 \mathrm{mg} / \mathrm{dl}$ of plasma.

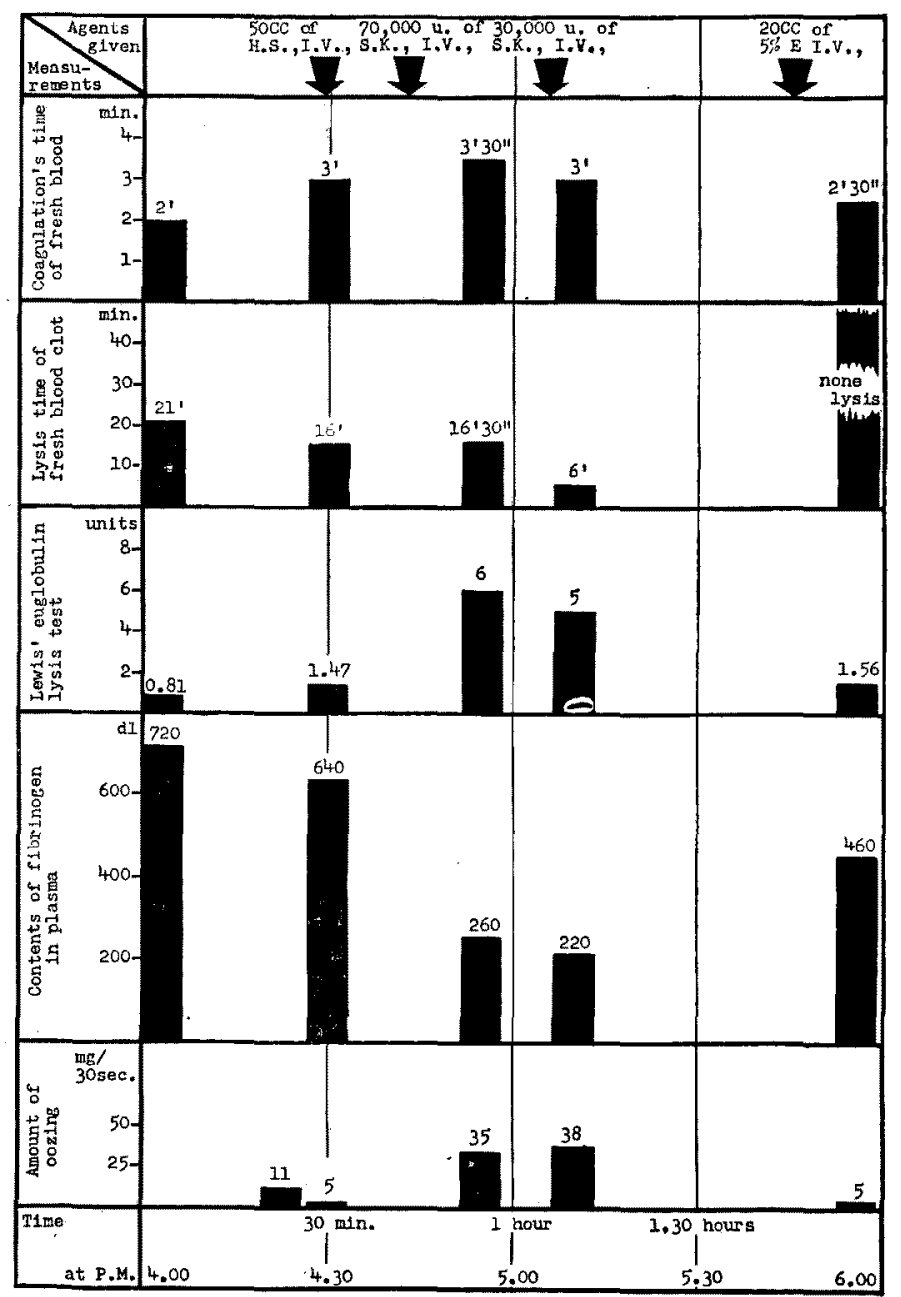

Fig. 3. Influence of $\varepsilon$ on high activity of plasmin and oozing caused by administration of human serum plus streptokinase. 
At 5:55 p.m., the blood pressure was $160-165 \mathrm{~mm} \mathrm{Hg}$ and oozing decreased distinctly to $5 \mathrm{mg} / 30 \mathrm{sec}$.

(7) This result showed that high plasmin activity in the blood and oozing caused by the administration of human serum plus SK, were distinctly suppressed by the intravenous administration of $\varepsilon$.

Case No. 6: Experimental Record No. 20. Date: April 24, 1959.

Dog's name: Orient II Adult, Sex: Male, Body weight: Ca. $12 \mathrm{~kg}$.

(1) Control blood sample was taken at 5:00 p.m. and plasmin activity was examined. i) Natural clot lysis test: The coagulation time was 5 minutes and lysis of the clot did not occur within 3 hours. ii) Lewis' euglobulin lysis test: Lower than 0.56 units $/ 0.5 \mathrm{cc}$ of plasma. iii) Whole clot lysis test: 3 days. iv) The content of plasma fibrinogen: $680 \mathrm{mg} / \mathrm{dl}$ of plasma.

At 5:00 p.m., the blood pressure was $165-166 \mathrm{~mm} \mathrm{Hg}$ and the amount of oozing was $9 \mathrm{mg} / 30 \mathrm{sec}$.

(2) At 5:50 p.m., $50 \mathrm{cc}$ of human serum was administered intravenously to the dog. and at 5:53 p.m. a second blood sample was taken. Plasmin activity was examined and the result was as follows: i) Natural clot lysis test: The coagulation time was 4 minutes an lysis of the clot did not occur within 3 hours. ii) Lewis' euglobulin lysis test: Less than 0.56 units $/ 0.5$ cc of plasma. iii) Whole clot lysis test: 3 days. iv) The content of plasma fibrinogen: $700 \mathrm{mg} / \mathrm{dl}$ of plasma.

At 5:00 p.m., the blood pressure was $160-162 \mathrm{~mm} \mathrm{Hg}$ and the amount of ooizng was $15 \mathrm{mg} / 30 \mathrm{sec}$.

This result showed that, by the sole administration of human serum, neither plasmin activity nor oozing tendency underwent any noticeable change.

(3) At 6:03 p.m., 50,000 units of SK was injected intravenously, whereby a transient fall of the blood pressure to $75 \mathrm{~mm} \mathrm{Hg}$ occurred at $6: 08 \mathrm{p.m}$., which recovered to normalcy after about 10 minutes.

(4) At 6:25 p.m., 30,000 units of SK was administered supplementally. The third blood sample was taken at 6:30 p.m. The plasmin activity of the sample was examined and the result obtained was as follows: i) Natural clot lysis test: The coagulation time was 1 minute and lysis time of the clot was 6 minutes. ii) Lewis' euglobulin lysis test: More than 10 units/0.5 ce of plasma. iii) Whole clot lysis test: 2 hours and a half. iv) The content of plasma fibrinogen was $160 \mathrm{mg} / \mathrm{dl}$ of plasma.

The amount of oozing increased to $115 \mathrm{mg} / 30 \mathrm{sec}$. at 7:35 p.m., and the blood pressure was $148-152 \mathrm{~mm} \mathrm{Hg}$.

This result indicated that a strong activation of plasmin and an increased oozing were produced by the administration of human serum plus SK.

(5) Twenty cubic centimetres of $5 \% \varepsilon$ solution was injected intravenously at 7:48 p.m. and supplemented by the intravenous administration of $20 \mathrm{ce}$ of $5 \% \varepsilon$ solution at $8: 43$ p.m.

The last blood sample of the experiment was taken at 8:46 p.m. The plasmin activity of the sample was examined and the result was as follows: i) Natural 
clot lysis test: The coagulation time was 4 minutes and lysis time of the clot was 11 minutes. ii) Lewis' euglobylin lysis test: 0.714 units/0.5 cc of plasma. iii) Whole clot lysis test: 4 days. iv) The content of plasma fibrinogen: 400 $\mathrm{mg} / \mathrm{dl}$ of plasma.

At 7:48 p.m.; the amount of oozing was $55 \mathrm{mg} / 30 \mathrm{sec}$ and the blood pressure was $180-190 \mathrm{~mm} \mathrm{Hg}$.

(6) This result showed that, by the administration of $\varepsilon$, high plasmin activity and oozing caused by the administration of human serum plus SK were distinctly suppressed.

Case No. 7: Experimental Record No. 22. Date: May 13, 1959.

Dog's name: Keiko Adult, Sex: Female, Body weight: Ca. $9 \mathrm{~kg}$.

(1) Control blood sample was taken at 5:08 p.m. The plasmin activity of the sample was examined. i) Natural clot lysis test: The coagulation time was 2 minutes and lysis of the clot did not occur within 3 hours. ii) Lewis' euglobulin lysis test: Less than 0.56 units $/ 0.5 \mathrm{cc}$ of plasma. iii) $\Delta$ of the absorbance at $280 \mathrm{~m} \mu$ U.V.: 0.056. iv) Whole clot lysis test: 4 days. v) The content of plasma fibrinogen: $570 \mathrm{mg} /$ dl of plasma.

The oozing was $5 \mathrm{mg} / 30$ sec at $5: 30$ p.m. and the blood pressure was $130-140$ $\mathrm{mm} \mathrm{Hg}$.

(2) At 5:45 p.m., $50 \mathrm{cc}$ of human serum was injected intravenously. At 5:51 p.m., the second blood sample was taken. Plasmin activity was examined and the result obtained was as follows: i) Natural clot lysis test: The coagulation time was 1 minute 15 seconds and lysis of clot did not occur within 3 hours. ii) Lewis' euglobulin lysis test: Less than 0.56 units $/ 0.5 \mathrm{cc}$ of plasma. iii) $\Delta$ of the absorbance at $280 \mathrm{~m} \mu$ U.V.: 0.017 . iv) Whole clot lysis test: 4 days. v) The content of plasma fibrinogen: $590 \mathrm{mg} / \mathrm{dl}$ of plasma.

The blood pressure was $130-140 \mathrm{~mm} \mathrm{Hg}$.

(3) At 6:04 p.m., 50,000 units of SK, dissolved in $5 \mathrm{cc}$ of physiological saline solution, was injected intravenously into the dog. At 6:13 p.m., the third blood sample was taken and the amount of oozing increased to $25 \mathrm{mg} / 30 \mathrm{sec}$. The plasmin activity of the sample was examined and the result obtained was as follows: i) Natural clot lysis test: The coagulation time was 2 minutes 10 seconds and the lysis time of the clot was 3 minutes 15 seconds. ii) Lewis' euglobulin lysis test: More than 50 units $/ 0.5 \mathrm{cc}$ of plasma. iii) $\Delta$ of the absorbance at $280 \mathrm{~m} \mu$ U.V.: 0.160 . iv) Whole clot lysis test: 30 minutes. v) The content of plasma fibrinogen: 180 $\mathrm{mg} / \mathrm{dl}$ of plasma.

The amount of oozing increased to $50 \mathrm{mg} / 30 \mathrm{sec}$ at $6: 18 \mathrm{p} . \mathrm{m}$. and the blood pressure was $125-130 \mathrm{~mm} \mathrm{Hg}$.

(4) This result showed that plasmin activity in the blood was extremely accelerated and oozing was increased several times by the administration of human serum and SK.

(5) At 7:07 p.m., $20 \mathrm{cc}$ of $5 \% \varepsilon$ solution was administered intravenously. Then twice at 7:40 p.m. and 8:14 p.m., injections of $20 \mathrm{cc}$ of $5 \% \varepsilon \varepsilon$ solution were carried out. 
The last blood sample was taken at $8: 21$ p.m. The plasmin activity of the sample was examined and the result was as follows: i) Natural clot lysis test: The coagulation time was 5 minutes 50 seconds and lysis of the clot did not occur within 3 hours. ii) Lewis' euglobulin lysis test: 0.83 units $/ 0.5$ ce of plasma. iii) $\Delta$ of the absorbance of $280 \mathrm{~m} \mu \mathrm{U} . \mathrm{V}$. turned negative. iv) Whole clot lysis test: 5 days. v) The content of plasma fibrinogen: $240 \mathrm{mg} / \mathrm{dl}$ of plasma.

At 8:21 p.m., the amount of oozing was $24 \mathrm{mg} / 30 \mathrm{sec}$ and the blood pressure was $130-140 \mathrm{~mm} \mathrm{Hg}$.

(6) This result showed that intense plasmin activity and oozing, which had been caused by the administration of human serum and SK, were decreased by the repeated administration of $\varepsilon$.

e) Influence of the preliminary administration of $\varepsilon$ on the activation of plasmin and oozing caused by the administration of human serum and SK.

Case No. 8: Experimental Record No. 7. Date: Nov. 13, 1958.

Dog's name: Marie Adult, Sex: Female, Body weight: Ca. $9 \mathrm{~kg}$.

(1) Control blood sample was taken at 3:45 p.m. The plasmin activity of the sample examined was as follows: i) Natural clot lysis test: The coagulation time was 4 minutes 45 seconds and lysis of the clot did not occur within 3 hours. ii) Lewis' euglobulin lysis test: 0.5 units $/ 0.5 \mathrm{cc}$ of plasma. iii) $\Delta$ of the absorbance at $280 \mathrm{~m} \mu \mathrm{U}$.V. was not detectable. iv) The content of plasma fibrinogen: $950 \mathrm{mg} / \mathrm{dl}$. At 4:25 p.m., the amount of oozing was $1 \mathrm{mg} / 30 \mathrm{sec}$ and the blood pressure was $100 \mathrm{~mm} \mathrm{Hg}$.

(2) At 4:33 p.m., $20 \mathrm{cc}$ of $5 \% \varepsilon$ solution was injected intramuscularly and at 4:35 p.m. $40 \mathrm{cc}$ of $5 \% \varepsilon$ solution was injected intravenously. At $4: 40$ p.m., $50 \mathrm{cc}$ of human plasma, which had received Castellani's absorption with the dog's erythrocytes, was administered intravenously and, at 4:54 p.m., 50,000 units of SK was also injected intravenously into the dog. The plasmin activity of the second blood sample, which was taken at 4:56 p.m., was as follows: i) Natural clot lysis test: The coagulation time was 5 minutes 30 seconds and clot lysis occured 30 minutes later. ii) The content of plasma fibrinogen: $230 \mathrm{mg} / \mathrm{dl}$ of plasma. At 5:00 p.m., the blood pressure fell transiently to $80 \mathrm{~mm} \mathrm{Hg}$, but it recovered within 5 minutes. The amounts of oozing measured at 5:00 p.m. and at 5:10 p.m. were both $0 \mathrm{mg} /$ $30 \mathrm{sec}$.

(3) This result showed that the preliminary administration of $\varepsilon$ was effective in suppressing the activation of plasmin in plasma and oozing caused by the administration of human serum plus SK.

Case No. 9: Experimental Record No. 23. Date: May 22, 1959.

Dog's name: Hercules Adult, Sex: Male, Body weight: Ca. $11 \mathrm{~kg}$.

(1) Control blood sample was taken at 4:25 p.m. The plasmin activity of the sample was as follows: i) Natural clot lysis test: The coagulation time was 3 minutes 30 seconds and lysis of the clot did not occur within 3 hours. ii) Whole clot lysis test: 4 days. iii) The content of plasma fibrinogen: $1,000 \mathrm{mg} / \mathrm{dl}$ of plasma. The 
blood pressure was $140-150 \mathrm{mg} \mathrm{Hg}$.

no noticeable oozing could be observed.

(2) At 4:39 p.m., $40 \mathrm{cc}$ of $5 \% \varepsilon$ solution was administered intravenously and $20 \mathrm{cc}$ of $5 \% \varepsilon$ solution was given intramuscularly. The second blood sample was taken at 4:46 p.m. The plasmin activity of the sample examined was as follows: i) Natural clot lysis test: The coagulation time was 2 minutes 40 seconds and lysis of the clot did not occur within 3 hours. ii) Whole clot lysis test: 4 days. iii) The content of plasma fibrinogen: $1,010 \mathrm{mg} / \mathrm{dl}$ of plasma.

The amount of oozing was $5 \mathrm{mg} / 30 \mathrm{sec}$ and the blood pressure $150-160 \mathrm{~mm} \mathrm{Hg}$ at $4: 43 \mathrm{p} . \mathrm{m}$.

(3) At 4:52 p.m., $50 \mathrm{cc}$ of human serum was administered intravenously and at 5:04 p.m., 50,000 units of SK was injected intravenously. The third blood sample was. taken at 5:06 p.m. The plasmin activity of the sample was as follows: Natural clot lysis test: The coagulation time was 1 minute and lysis of the clot did not occur within 3 hours.

The blood pressure fell slightly from $165-175 \mathrm{~mm} \mathrm{Hg}$ to $140-145 \mathrm{~mm} \mathrm{Hg}$, but immediately it recovered to the former level after 10 minutes. The amount of oozing was $5 \mathrm{mg} / 30 \mathrm{sec}$ at $5: 08 \mathrm{p} . \mathrm{m}$.

This result showed that, by the preliminary administration of $\varepsilon$, plasmin activity and oozing were not increased in spite of the administration of $50 \mathrm{cc}$ of human serum and 50,000 units of SK.

(4) The supplementary administration of 50,000 units of SK was provided intravenous-

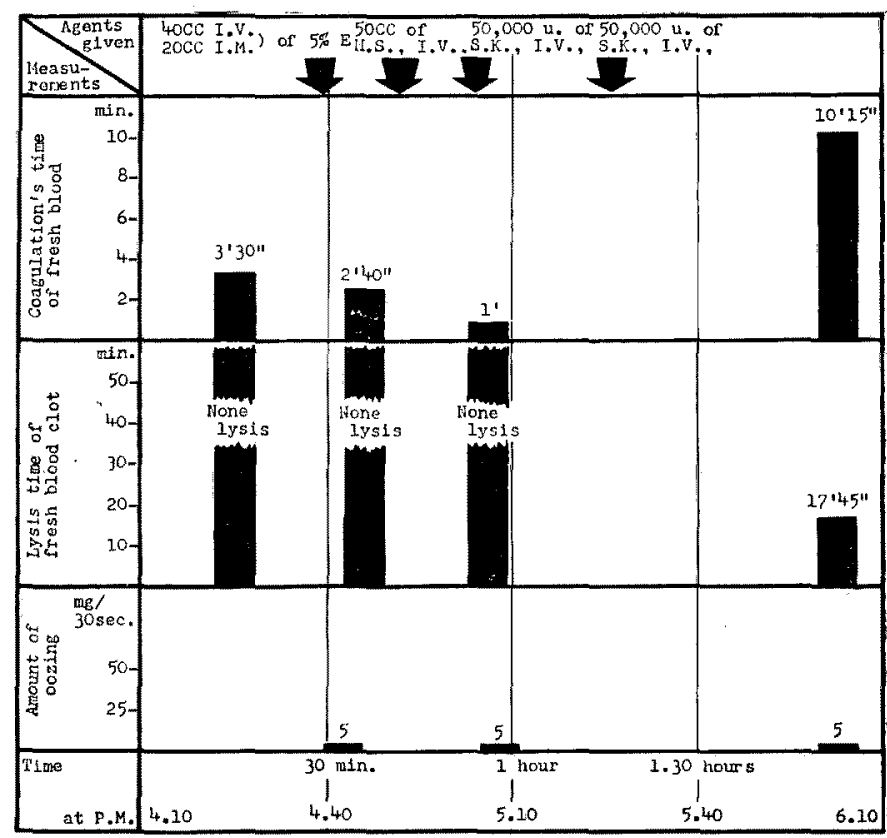

Fig. 4. Influence of the preliminary administration of $\varepsilon$ on the activation of plasmin and oozing caused by the administration of human serum and S.K. 
ly at $5: 26$ p.m.

45) The blood sample which was taken at 6:03 p.m. at the end of this experiment was as follows: i) The coagulation time of fresh blood was 10 minutes 15 seconds and the lysis time of this clot was 17 minutes 45 seconds later. ii) Whole clot lysis test: Coagulation did not occur. iii) The content of plasma fibrinogen: 150 $\mathrm{mg} / \mathrm{dl}$ of plasma. The blood pressure was $145-150 \mathrm{~mm} \mathrm{Hg}$. The amount of oozing was $5 \mathrm{mg} / 30 \mathrm{sec}$.

This result showed that the preliminary administration of $\varepsilon$ was effective in suppressing the activation of plasmin of plasma and oozing caused by the administration of $50 \mathrm{cc}$ of human serum and of the total of 100,000 units of SK which previously proved to be sufficient to produce the activation of plasmin and an obvious oozing.

f) Infuence of the administration of $\varepsilon$ on the oozing tendency caused by the administration of Heparin.

Case No. 10: Experimental Record No. 18. Date: April 20, 1959.

Dog's name: Pegasus Adult, Sex: Male, Body weight: Ca. $12 \mathrm{~kg}$.

This experiment was carried out in order to ascertain whether the administration of $\varepsilon$ was effective against the oozng tendency which was caused without significant change of plasmin by another anti-coagulant Heparin. During the experiment, oxygen gas was provided to the dog through tubes inserted intratracheally.

(1) The amount of oozing measured at $6: 15 \mathrm{p.m}$. was $11 \mathrm{mg} / 30 \mathrm{sec}$.

(2) At 6:25 p.m., $50 \mathrm{mg}$ of Heparin was injected intravenously. At 6:30 p.m., oozing occurred from the incised wound, and the amount of oozing increased to $75 \mathrm{mg}$ / $30 \mathrm{sec}$.

(3) At 6:36 p.m., the supply of oxygen gas was stopped, and the trachea tube was narrowed to produce the anoxic state in the dog. Oozing was intensely increased with the disturbance of ventilation. At $6: 45$ p.m., the amount of oozing became as remarkable as $205 \mathrm{mg} / 30 \mathrm{sec}$.

(4) At 6:55 p.m., the narrowed trachea tube was reopened and the supply of oxygen gas was again provided; oozing decreased thereafter. At 7:10 p.m., the amount of oozing was $46 \mathrm{mg} / 30 \mathrm{sec}$.

(5) At 7:15 p.m., the trachea tube was narrowed again to a quarter of the original area and the supply of oxygen gas was stopped. Oozing resumed and increased. At 7:25 p.m., the amount of oozing was $165 \mathrm{mg} / 30 \mathrm{sec}$.

(6) At 7:42 p.m., $20 \mathrm{cc}$ of $5 \% \varepsilon$ solution was administered intravenously to the dog during the state of anoxia, but the increased oozing was not suppressed. The amount of oozing, which was measured 5 minutes after the injection of $\varepsilon$, was $183 \mathrm{mg} / 30 \mathrm{sec}$.

(7) Resuming the supply of oxygen gas at 8:08 p.m., the oozing clearly decreased to $40 \mathrm{mg} / 30 \mathrm{sec}$ at $8: 13$ p.m.

(8) Plasmin activity examined during the course of the experiment showed no significant change. 
(9) This result showed (i) that oozing occurred more or less after the intravenous administration of Heparin, (ii) that, during the anoxic states, oozing increased 5 tiems and (iii) that the administration of $\varepsilon$ was not effective in lessening oozing caused by Heparin. Attention was paid to these results, in which activation of plasmin was not observed in bleeding caused by Heparin.

From this evidence, it is clear that oozing can be produced not only by the activation of plasmin, but also by the administration of Heparin plus anoxia. Emphasis is placed on the evidence that $\varepsilon$ was not effective against oozing caused by Heparin plus anoxia.

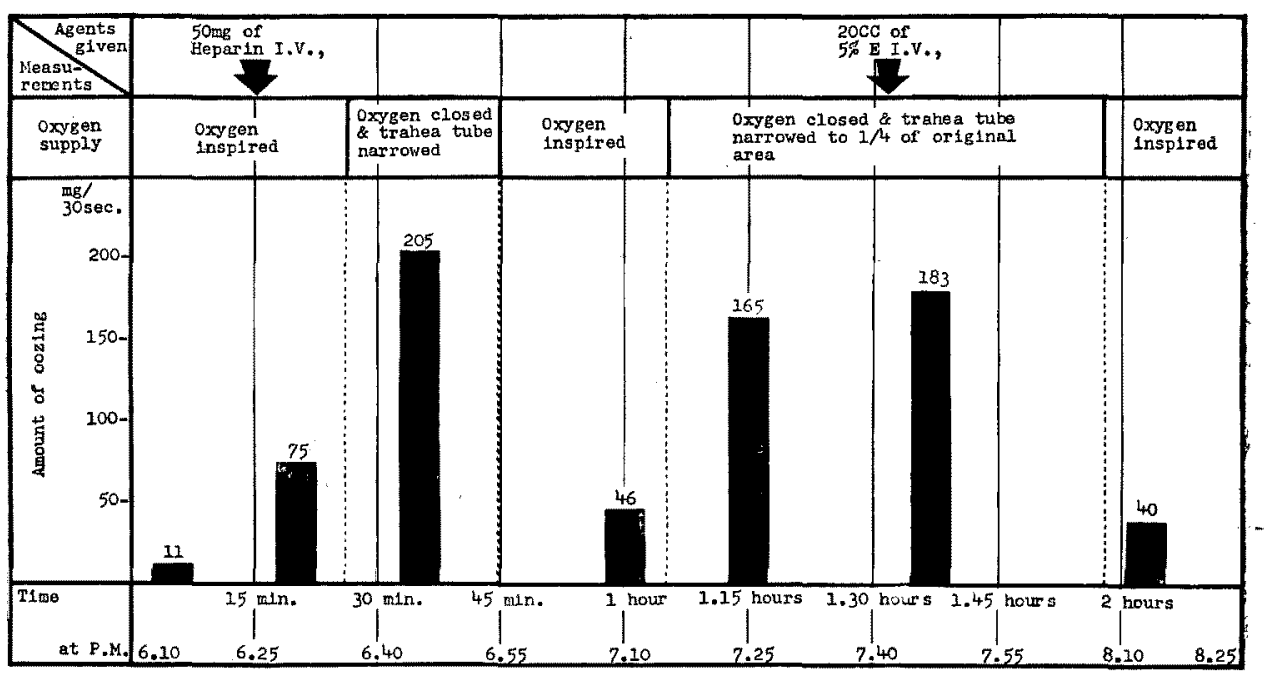

Fig. 5. Influence of $\varepsilon$ on the oozing tendency caused by the administration of heparin.

\section{DISCUSSION}

It is known that the intravenous, sole administration of SK to dogs resulted in slight or no activation of plasmin in the circulatory blood. In fact, the results obtained from cases Nos, 1 and 2 showed that there was only a weak response of the plasmin system of dogs to the intravenous, sole administration of a sufficient amount of SK.

Results obtained from cases Nos. 3, 4, 5, 6 and 7 showed that no change of the plasmin system in the blood of dogs occurred by the intravenous, sole administration of human serum which underwent the mentioned Castellani's absorption.

The effect of the intravenous administration of human serum plus SK to. dogs was examined in cases Nos. 3, 4, 5, 6, and 7.

(1) Plasmin activity was observed to be very strongly activated in the circulatory blood of dogs, when examined by the method of natural clot lysis tests of 
fresh blood carried out at $37^{\circ} \mathrm{C}$, euglobulin lysis test(5), the measurements. of extinction of $280 \mathrm{~m} \mu$ Ultraviolet test(6) and whole clot (plasma clot) lysis test(7).

(2) When plasmin in the circulatory blood was strongly activated by the intravenous administration of human serum plus SK, a distinct increase of bleeding i.e. an increased oozing from the incised wound was recorded.

By the intravenous administration of $\varepsilon$ which was carried out after the occurrence of an obvious oozing with the activation of plasmin system in dogs, the inhibition of the activity of plasmin in the circulatory blood of dogs and the decrease of the oozing tendency from the incised wound were both observed. These results were demonstrated in cases Nos. 4, 5, 6 and 7.

Effects of $\varepsilon$ administrated intravenously to dogs prior to the administration. of human serum plus SK were demonstrated in results obtained from cases Nos. 8 and 9 . These results showed that the preliminary administration of $\varepsilon$ diminished the degree of the activation of plasmin to be caused by the intravenous administration of human serum plus SK and prevented the occurance of any noticeable oozing, which could appear after the intravenous administration of human serum plus SK without the previous administration of $\varepsilon$.

We summarize (1) that, when plasmin activity in the circulatory blood of dogs was fully activated by the intravenous administration of human serum plus SK, an increased oozing from the incised wound occurred, and (2) that, by the administration of $\varepsilon$, the activation of the plasmin system in the blood. and the oozing from the incised wound were clearly suppressed.

It was previously mentioned by us that the activation of the plasmin system in the circulatory blood or possibly in the locus can be a cause of some kindsof disorders, and that the administration of $\varepsilon$ to patients suffering from such disorders was effective in combating the activation of plasmin and in treatingthe disorder associated with the activation of plasmin system(4).

Though we have not neglected the possibility that the activation of plasmin in some pathologic states can be produced by a more primary or more profound "cause" such as the release of cytoactivator of plasmin from the injured tissue or the occurrence of antigen antibody reaction in case of diseases suspected to be allergic, emphasis should be placed on another aspect of the activation of plasmin; that is, the activation of plasmin and the resultant high activity of plasmin can be "a cause" of some pathologic states such as bleeding with hypofibrinogenemia or disturbed mechanism of clot formation in more or less injured regions. If, by some example the activation of plasmin can be regarded to be the result of another injury, such illustration does not deny the possibility that 
the activated plasmin can be a direct cause of disorders such as bleeding.

We say, after reasonable consideration, (1) that the model experiments in dogs to produce pathologic states with high activation of plasmin in the blood and to improve the state with the administration of $\varepsilon$, presented sufficiently scientific evidence, confirming the relation of cause and effect of antiplasmin therapy, (2) that the evidence demonstrated here coincided with the clinical evidence, that is, the administration of $\varepsilon$ was effective in combating the activation of plasmin and the related pathologic states, and (3) that the method to combat the activation of plasmin system or high activity of plasmin in the circulatory blood with the administration of $\varepsilon$ can be merit and of utility in treating the pathologic states associated with and caused by the activation of the plasmin system or high activity of plasmin.

The following are naturally deduced from the evidence demonstrated above:

(1) A strong activation of plasmin in the blood experimentally produced can cause an increased bleeding tendency of dogs.

(2) The activation of plasmin and high plasmin activity in the blood as well as an increased tendency of oozing was clearly suppressed by the intravenous administration of $\varepsilon$ which was carried out either prior or posterior to the experimental process of activating plasmin in the blood.

(3) Such an increased tendency of oozing as made by giving Heparin and producing an experimental anoxia in dogs was not accompanied by any signs of the activation of plasmin in the blood, nor improved at all by the intravenous administration of $\varepsilon$.

(4) The experimental activation of plasmin in the blood in these experiments was not a result but a cause of the increased tendency of oozing.

(5) The activation of plasmin found in the blood of some kinds of patients is not a simple, final result, but it can be a cause of bleeding or other associated disorders, as previously stated by us.

The essential evidence of the antiplasmic therapy, that is, the successful application of $\varepsilon$ in suppressing the activation of plasmin or high plasmin activity of human blood and in treating those kinds of diseases which were accompanied and regarded to be caused by the activation of plasmin in the blood, was reproduced and experimentally confirmed by the obvious evidence obtained from the mentioned animal experiments. The typical coincidence is found between the clinical and the experimental evidence: In such disorders as (i) bleeding in metropathia hemorrhagica ${ }^{(8)}$, bleeding tendency of aplastic anemia or leucemia(9) which were revealed by the other members of the project at School of Medicine, Keio University, and as (ii) oozing experimentally produced in dogs, high activity 
of plasmin of the blood and the increased bleeding tendency were both at the same time observed, and the suppression of the high plasmin activity by the administration of $\varepsilon$ resulted in the distinct improvement of the above-mentioned bleeding.

It was reasonably deduced from the evidences described in the present paper, that the method to combat the activation of plasmin system or high activity of plasmin in the circulatory blood by the administration of $\varepsilon$ can be available in treating the pathologic states associated with and caused by the activation of plasmin system or high activity of plasmin.

\section{SUMMARY AND CONCLUSION}

a) It was demonstrated in these experiments that the intravenous administration of a specially prepared human serum and a certain amount of SK resulted in a strong activation of plasmin and a decrease of plasma fibrinogen in the circulatory blood of dogs.

b) It was also recognized that high activity of plasmin in the circulatory blood of dogs was distinctly accompanied by the marked increase of bleeding, i.e. the oozing tendency from incised wounds of the skin of dogs.

c) It was proved that the intravenous administration of a certain amount of $\varepsilon$ was effective in suppressing the bleeding tendency as well as high plasmin activity in the blood, both of which had been produced by the mentioned procedure.

d) The intravenous administration of $\varepsilon$, which had been undertaken prior to the intravenous administration of human serum and SK, was very effective in arresting the occurrence of the oozing tendency and the activation of plasmin in those dogs which received the intravenous administration of human serum and SK.

e) However, the intravenous administration of $\varepsilon$ was not effective in arresting the oozing tendency of dogs which had the preliminary intravenous administration of a physiological saline solution containing $50 \mathrm{mg}$ of Heparin sulfate and experimental anoxia. It was in particular noticed that the activity of plasmin was unchanged in this case.

\section{REFERENCES}

1. Cornell, J. F. Jr. and Rousselot, L. M.: The Evaluation of Anti-Inflammatory Drugs in Surgical Lesions. Ann. New York Academy of Science 68. Art 1:155, 1957.

2. Sherry, S., Fletcher, A. P., and Alkjaersig, N.: Fibrinolysis and Fibrinolytic 
Activity in Man. Physiol. Rev. 39:343, 1959.

3. Ratnoff, O. D.: A Fatal Hemorrhagic State associated with Excessive Plasma Proteolytic Activity in a Patient undergoing surgery for Carcinoma of the Head of the Pancreas. J. Clin. Invest. 31:521, 1952.

4. Okamoto, S. et al. (1953) : Refer to British Patent, 1957. No. 770,693 (Mitsubishi Kasei Kogyo Co., Ltd.).

5. Lewis, J. H. and Fergusson J. H.: Studies on a Proteolytic Enzyme System of the Blood. I. Inhibition of Fibrinolysin. J. Clin. Invest. 29:486, 1950.

6. Ungar, G., Damgaard, E., and Hummel, E. P.: The Fibrinolysin-Anti-Fibrinolysin System in Serum; Mechanism of its Endcrine Control. Endocrinology 49:805, 1951.

7. Ratnoff, O. D.: Studies on a Proteolytic Enzyme in Human Plasma. IV. Bull. Johns Hopkins Hosp. 84:29, 1949.

8. Sato, S., Ishibashi, Y., Endo, T., Watanabe, T., and Nakajima, K.: Clinical Use of $\varepsilon$-Amino-Caproic Acid on Metropathia Hemorrhagica. Keio J. Med., 8:267, 1959.

9. Mikata, I., Hasegawa, Y., Igarashi, T., Shirakura, N., Hoshida, M., and Sotoyama, K.: Variation of Plasmin in the Hemorrhagic Blood Diseases. Keio J. Med., $8: 279,1959$. 